\title{
A Distributed Generation System with Micro Grid for Effective Energy Management
}

\author{
Kalluri Deepika \\ CVR College of Engineering/EEE Department, Hyderabad, India \\ Email: deepika.kalluri@gmail.com
}

\begin{abstract}
A Distributed generation (DG) system with Micro grid(MG) powered by the renewable energy sources like solar, wind and fuel cells along with the battery is under study. The profile of the power consumed from the grid and the power delivered back to the grid is found. The load forecasting data is considered by the Microgrid system simulation with industry and domestic loads and it is observed that the load demand is met efficiently with the available energy resources and some part of the energy is fed back to the grid as well. Also, the voltage at the PCC is observed with different loads such as domestic loads and industry loads.
\end{abstract}

Index Terms-Distributed Generation, Microgrid, Fuel Cell, Wind Energy, Solar Energy, load forecasting

\section{INTRODUCtion}

Today, the local energy generation is very prominent for the sustainability of energy for future. Distributed generation system refers to the energy generated at the consumer point. A microgrid along with the distributed generation system can be used as a backup for the grid in case of emergencies like grid outages. A microgrid system gives scope for greener energies and also has advantages of providing flexible electricity. Therefore, with the microgrid systems, the consumers become more energy independent and environment-friendly.

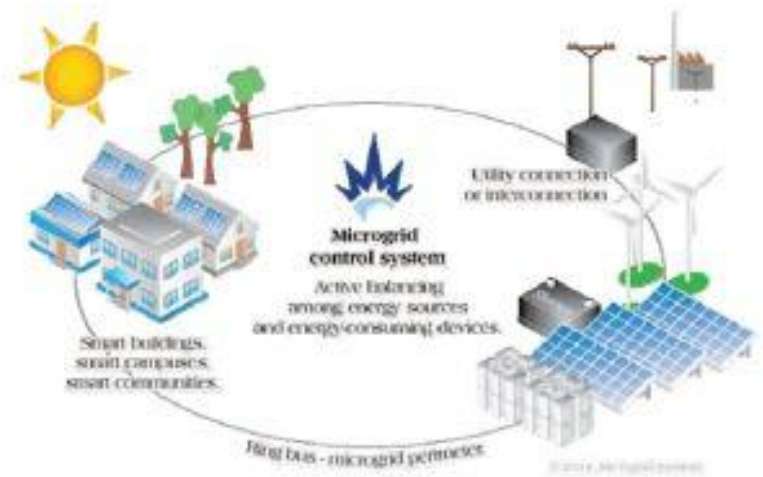

Figure 1. Schematic of a Microgrid with utility Interconnection

A microgrid is powered by renewable resources like wind energy, solar energy, fuel cell and the backup diesel generators, batteries. [1] The microgrid infrastructure provides the platform for efficiency improvement and enhanced energy consumption within a small area. Power generation happening at the load end reduces the transmission losses. Also, the distribution system is comparatively less complex in construction. The load is considered uncontrolled in most of the situations, and hence the required amount of power must be generated dynamically. With the conventional power plants, there are primary and secondary load control mechanisms. However, the scenario is different here and unconventional control of the source must be considered. The sources considered here are Solar Photovoltaic, Fuel-cell, and power from wind energy. Out of these, the solar and wind power generated is purely dependent on the solar insolation levels, and wind power output depends on the wind speed available. Fuel cell power output is controllable as the hydrogen and oxygen inputs are controlled at the inlet value. Normally combined heat and power is considered as a source but for Indian conditions, heat is not available naturally in a large scale. So it is not considered in the simulation. It is observed that efficiently managing the resources could save the operating cost of the system and hence more profits can be obtained. The coordination of the supply from different sources increases the overall efficiency of the system. It is a recommended practice to also have the power supply connection from the grid. This helps in meeting the load demand with the generation possible at the load end with the renewable energy sources and the balance load demand is met by the grid. Whenever the load is completely met by the generation from these renewable energy sources and there is excess power available, it is required to feed the excess power back to the grid. The power exchange can be measured to observe whether the power is taken from the grid or the power is fed back to the grid. This is called NetMetering. [2]

Considering the operation of the microgrid, traditionally there are two modes. Mode 1: The Microgrid is connected to the main grid so that the power can be either consumed or delivered back to the grid. (Grid Connected Mode (GCM)) [3]. Mode 2: The Micro grid is disconnected with the grid during the emergencies and has the capability to run the local loads. (Islanded Mode) [4]. A typical Microgrid System with utility connection is shown in figure 1.

It is also required to control the microgrid in the islanded and grid-connected modes [4]. [5]. A study is done on the energy management in the microgrid, in grid-connected mode and its effectiveness is discussed.

The contents of the paper are as follows. The first section gives the introduction to the problem addressed. The objectives are discussed in the second section. The methodology used for the analysis is explained in the third section. The results and discussions are in the fourth section followed by conclusions. 


\section{OBJECTIVES}

This study is meant to understand the power exchange at the point of common coupling and role of net-metering when different types of loads are connected to the system. A Microgrid is the next generation system architecture. So, the loads and sources are modeled and connected to the system to form a microgrid. As the loads are consuming power, if there is not enough power generation available, the voltage at the point-of-common-coupling would drop. Load shedding may be considered as an option, but the reliability indices will go down and this is not accepted by the consumer as promised power quality has to be supplied. There may also be a penalty for power-not-supplied. Hence power has to be supplied from some source to assist the internal power generation. For this purpose, power is bought from the grid. The grid also welcomes power to be supplied to it when the voltage and frequency requirements according to the IEEE standards are met.

Another objective is to study how the single phase loads connected to the three phase supplies are effecting the voltage profile at the bus. This is considered important as uneven voltages in the three phase at the point-of-commoncoupling will result in the flow of neutral-currents for which the system is not designed for. Here, household load is assumed to be connected to Phase-a, the small-scale industrial load is connected to Phase-b and a three-phase heavy industrial load is connected to all the phases so that the power drawn from phase-a is comparatively less than that of Phase-b while Phase-c supplying the least. The scenario would be different when power is fed back to the grid from the loads and is to be analyzed.

\section{Methodology}

The Microgrid system at the distribution side is taken into consideration. It is powered up by solar, wind, fuel cell and UPS. The micro grid system is connected to different types of loads like domestic load, industry load (connected to single phase) and Heavy Industry load (connected to three phase). This type of system is taken into consideration. Distributed generation system refers to the energy generated at the consumer point. At every point based on the load forecasting the generation- demand balance is met from the local generation and the grid.

At each load end, there are different types of power generators installed and connected to the load. Solar, fuel cell and wind powers along with a battery are considered to be generating power all day. Whenever there is enough power generation, there is no power drawn from the grid. If excessive power generation is available, power is supplied to the grid.

The data is taken from a dat format file which is given in the Appendix and respective column data is extracted. This is now analyzed and computed for the grid power consumed and the grid power supplied. This is traditionally called day-ahead power exchange prediction based on the forecasted load and generation availability. Energy management can also be implemented at this stage for optimized profitability but is considered to be beyond the scope of the paper. The methodology used is shown in figure 2 .

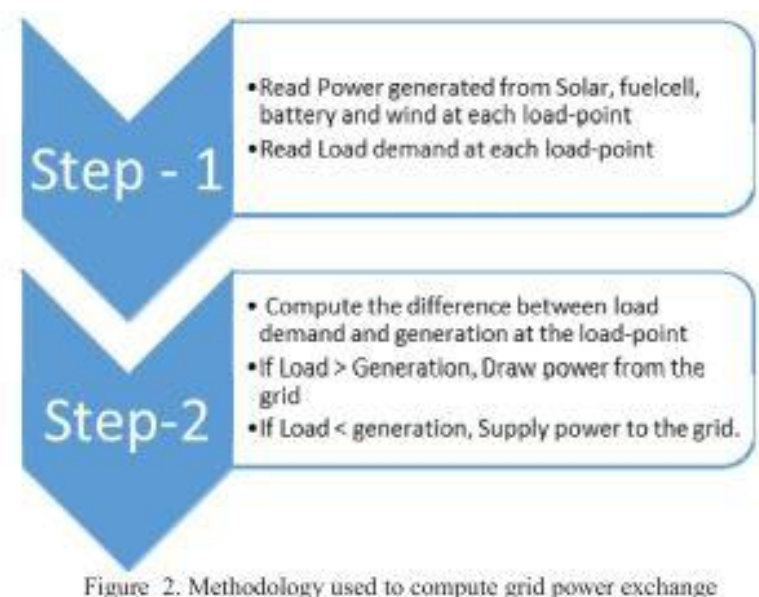

At each load point, the power drawn from the grid is assumed to be supplying the excessive load and hence the current and voltage associated with that load is observed. This power drawn is estimated by distributing the power among the split-phase load as $S_{1}$ and $S_{2}$ (virtual, represented as a current source connected in anti-parallel. The total power is randomly distributed. The relation between powers in the split phases is shown as:

$$
\begin{aligned}
& S \_1=S * \text { random }\left[\begin{array}{ll}
0 & 1
\end{array}\right] \\
& S \_2=S *\left(1-\text { random }\left[\begin{array}{ll}
0 & 1
\end{array}\right]\right)
\end{aligned}
$$

The current in each phase is computed as follows.

The relation between power assuming the reactive power $(\mathrm{Q}=0)$. Therefore, the apparent power is given by

$$
\begin{array}{cc}
S=\frac{1}{\sqrt{2}} V_{\text {rma }} \frac{1}{\sqrt{2}} l_{\text {rma }} \quad \text { if if } V_{\text {rms }}>0 \\
S=0 & \text { otherwise }
\end{array}
$$

Where $V_{\text {rms }}$ and $I_{\text {rms }}$ are the RMS voltage and current at the load point.

So, from equation 3 , the current expression can be derived as:

$$
b_{\text {rms }}=\frac{2 s}{V_{r m a}}
$$

The power that is drawn or supplied to the grid are to be managed in a way not to affect the voltage profile at the bus. The other things considered during the simulation are a) Meet the load demand by maintaining voltage and frequency within the limits.

b) Understand the benefits of adding a surplus power generation.

c) Analyze the power market situations, provide custom components to control the load to be operated during maximum internal power generation at the load center.

d) Setting up communication interfaces between load and control center.

e) Study of the effect of addition of load on the system on a phase.

The load data and the data of generation available at the load end is assumed to be known by forecasting techniques. The power that has to be exchanged from the grid is precalculated so that the benefits can be analyzed. The street- 
lighting and other auxiliary loads are assumed to be constant and are included as a RL model. There is no reserve considered in this model and can be the future enhancement of the paper.

\section{Simulation, RESUlts AND Discussion}

\section{A. MATLAB based simulation}

A Distributed generation system with solar, wind fuel cell and the batteries[1] connected to a microgrid is simulated in the MATLAB-Simulink environment.

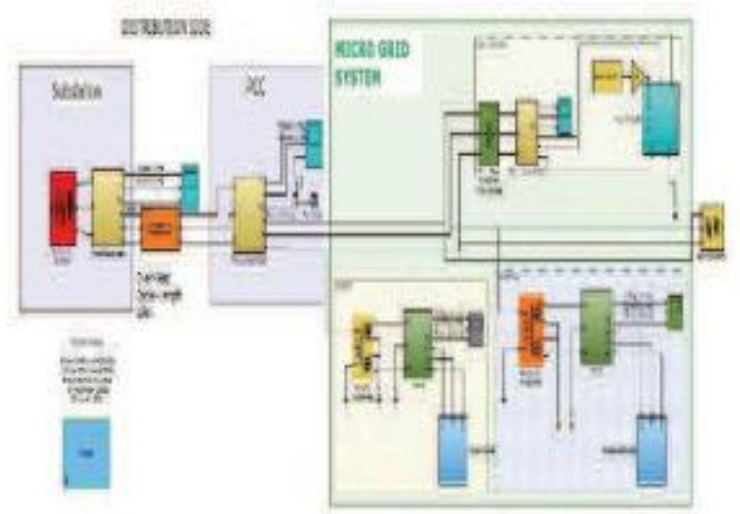

Figure 3. MATLAB-SIMULINK Model

The developed micro grid system can be simulated for the required time, i.e. the load forecasting can be done for $6,12,18,24 \mathrm{hrs}$, as per requirement to understand the voltage fluctuations and power exchange between the utility grid and microgrid.

The MATLAB-Simulink model is as shown in the figure 3. This system includes a three phase grid supply, a small transmission line and loads connected at PCC. The micro grid system is modeled with different types of load like domestic load, small scale industry loads and heavy industry load, modelled as a current source, connected in anti-parallel, as if drawing the amount of load current from the grid.

Further industry and house are modeled as shown in the figure 4. Each house load or industry load is further divided number of loads. A sample Industry load is shown in the figure 4 .

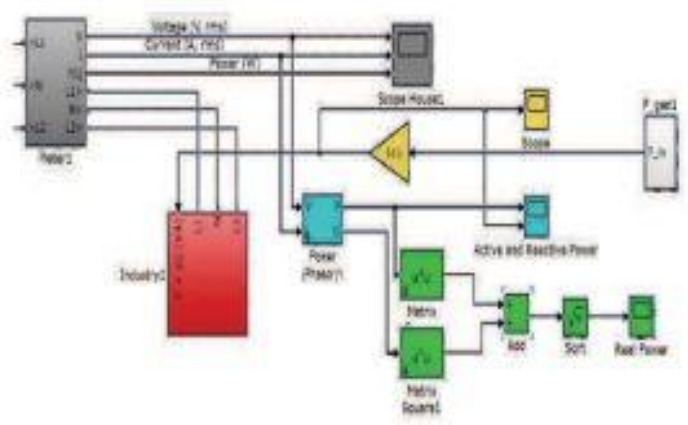

Figure 4. Small Scale Industry/House Model

A domestic load is modeled with 5 different house loads. A small-scale industry is modeled with five different industries. Both the above loads are simulated as a singlephase loading. A heavy industry load is modeled which is a 3-Ph load. Analysis on the model is done for three different cases.

Case A: All the connected loads in the MG system are assumed to be domestic loads. In that case, the voltage fluctuations and power exchange at the PCC are as shown in the figure 5 \& 6 respectively.

Case B: In this case, along with the domestic loads, smallscale industry load is added. In that case, the voltage fluctuations and power exchange at the PCC are as shown in figure $7 \& 8$ respectively.

Case C: In this case, along with the domestic load, smallscale industry load, heavy industry load is also added. In that case, the voltage fluctuations and power exchange at the $\mathrm{PCC}$ are as shown in figure $9 \& 10$ respectively.

\section{B. Results}

The results for the three different cases simulated are shown in the following figures. It is to be noted that all the figure's $\mathrm{x}$-axis corresponds to a $24 \mathrm{hr}$ horizon, sampled at each minute.
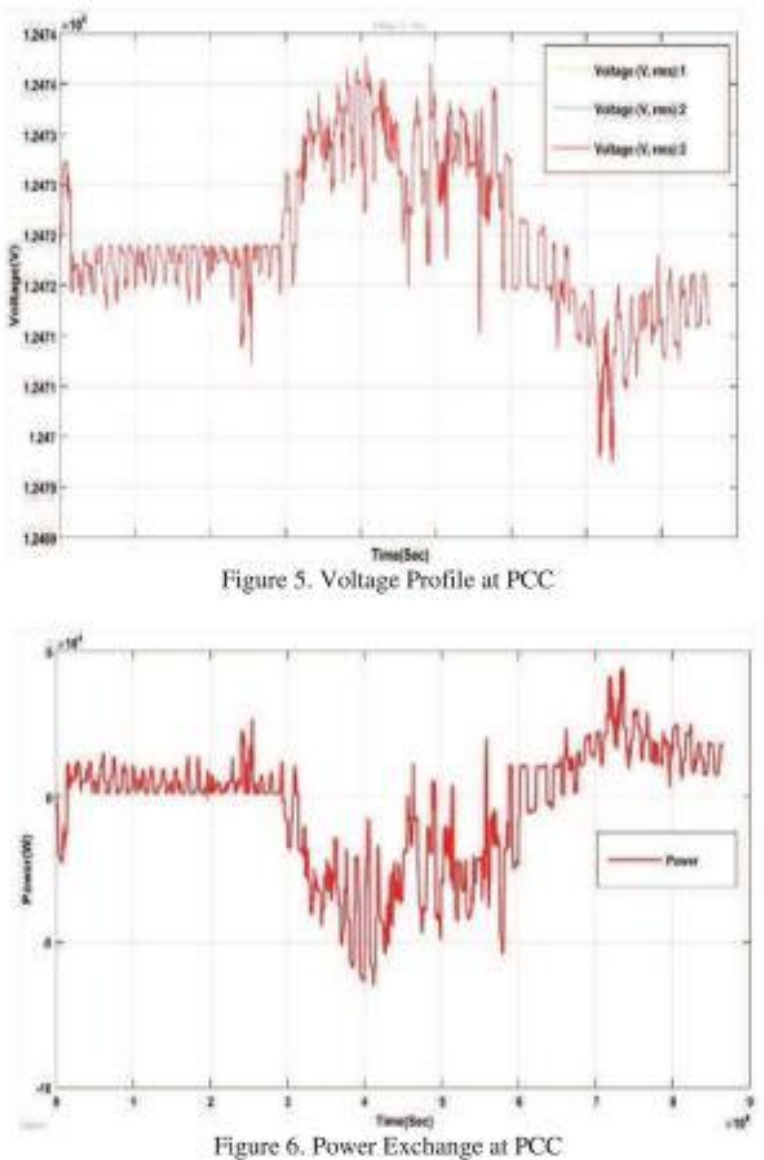

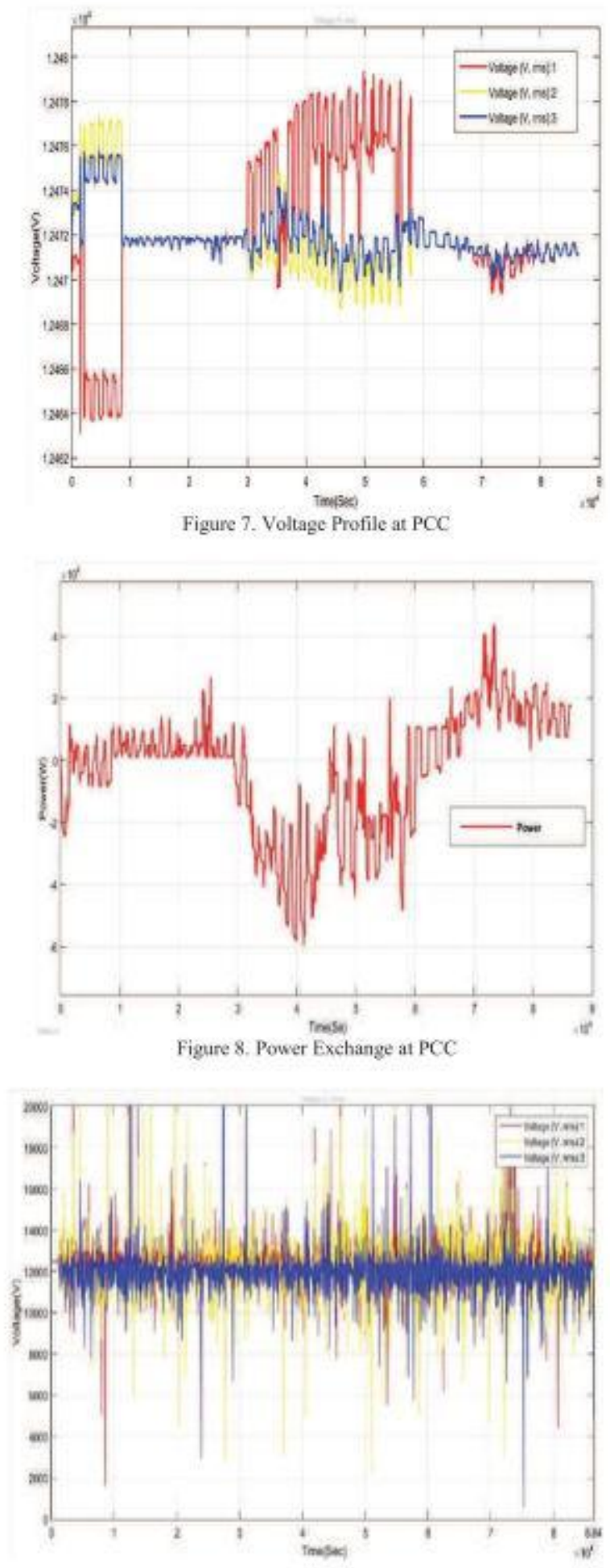

Figure 9. Voltage Profile at PCC

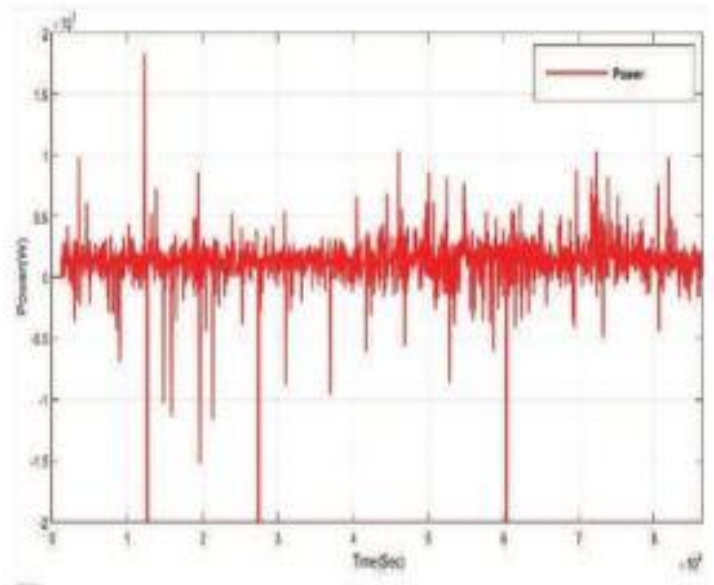

Figure 10. Power Exchange at PCC

The domestic load is further considered as five independent house loads and the power met by the load is shown in Fig 11. The domestic load for a sample load is shown as a solid line. The solar power generated during the day time is shown as a dotted line.

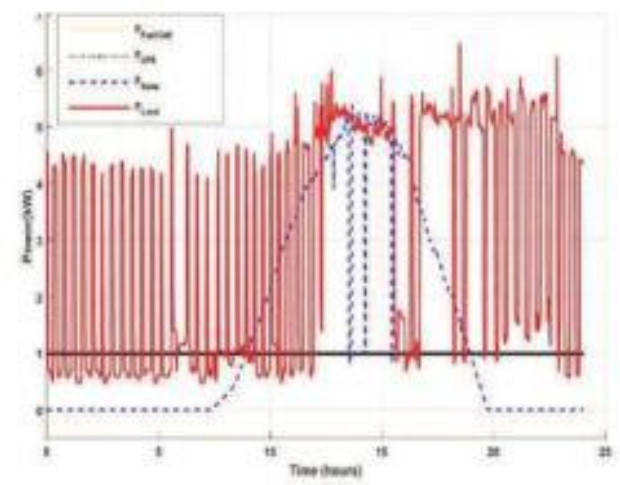

Figure 11. Power met by domestic load

The small-scale industry load is atso considered as five industries and power met by the load is shown in Fig 12. The industry load for a sample load is shown as a solid line. The solar power generated during the day time is shown as a dotted line. Whenever the power generated exceeds the demand the power is fed back to the grid as shown in the negative region.

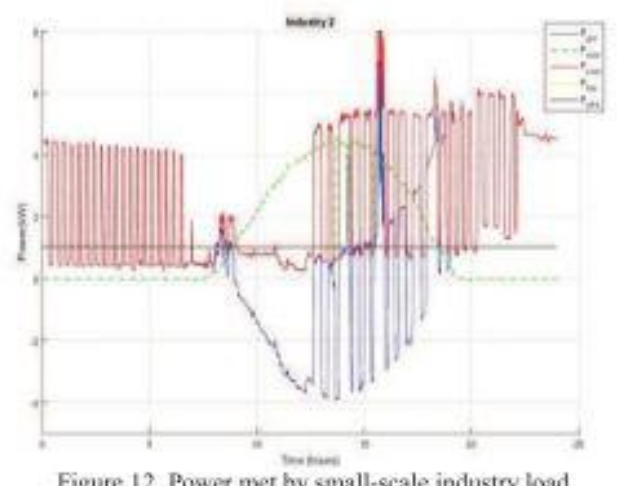

Figure 12. Power met by small-scale industry load 
The power met by the heavy industry load is shown in Fig 13 . This is also similar to the industry load discussed above.

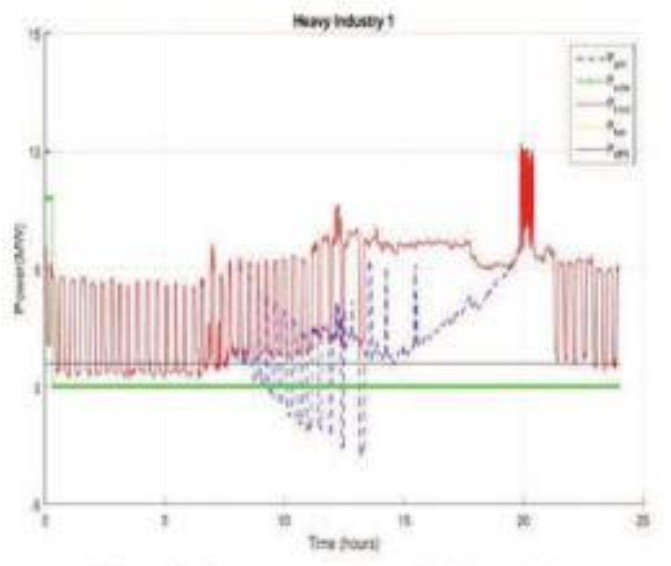

Figure 13. Power met by Heavy industry load

\section{Discussion}

It can be observed that always there is a power exchange between the utility grid and micro-grid. Whenever the load demand is not met by the local generation, the utility supplies the required power. Whenever there is an excess power in the micro grid it is sent back to the utility grid.

The rated voltage at the PCC is $12.47 \mathrm{kV}$. Whenever there is a power exchange happening from the grid, the voltage tends to change. In figure 4 , the voltage variation can be observed to be deviating from $99.98 \%$ to $100.03 \%$ of the rated value. This is well between the allowable deviation of $\pm 10 \%$. It can also be observed that the voltage is not different in different phases. The power exchange at the PCC can be analyzed from figure 5 . It is obvious from the graph that most of the time, the icrogrid is producing power not only enough for the local loads, there is a surplus of power available. So, the measured power shows negative values, indicating the flow from microgrid to the grid. There is a maximum feeding to the grid during noon time, due to the maximum power generation from Solar Photovoltaics.

The second case considered is the influence of the presence of a small-scale industrial load in the system, at a phase. Now this should cause unbalance in the system voltage, as different loads are connected on different phases. This can be observed in figure 6. Two household loads connected to two phases have similar voltage profile, while the third phase has a voltage which is fluctuating because of the quantity of load. It is again observed that the deviation is between $99.98 \%$ to $100.08 \%$, which is much less than the allowable $\pm 10 \%$.

The second observation is that the voltage fluctuations at the $\mathrm{PCC}$ are different in three cases. It can be observed that when the industry load is introduced along with domestic load at phase c, the fluctuations are more in that phase. When the heavy industry load is introduced, all the phases are disturbed showing high voltage and current fluctuations. The power exchange is again predominantly happening from the microgrid to the grid. Two conclusions can be made from figure 7 . Firstly, there is always a scope for adding additional load in the microgrid area and see that the power exchange is close to zero but in the negative region. Secondly, load can be scheduled to be connected to the microgrid during noon time. This can reduce the peak value in the graph to look flat, so that the power quality at the PCC is improved.

As mentioned in case 3 , figure 8 shows the voltage fluctuation, where the voltage deviation is found to be predominant in all the three phases. The deviation is happening between 91.42 to $104.25 \%$ of the rated. This is again within the standards. The voltage profile seems to now shift from the negative to the positive region, i.e., power is now drawn from the grid predominantly. During night time, there is much fluctuation in the power flow.

All the load demands are met by the energy sources available at the microgrid as well as the utility grid in all the three cases. The individual load profile shown in figure 10 and figure 11 shows that whatever is the load demand, that power is supplied after considering the available sources of fuel cell, solar, wind and battery power. The loads at household and industry are chosen in a way to see that there is always a load present and distributed among the $24 \mathrm{hr}$ horizon. The power coming from solar can be precisely found here. These are assumed to be rooftop solar photovoltaics installed. The fluctuation in the load is considered to check the stability of the system under such conditions and it is found that the sum of generation plus the grid power exchange is capable of supplying uninterrupted power to the load. This is desirable so as to maintain power quality at the load end.

\section{Conclusions}

In the paper, the Micro-grid system that connects the household loads and various industry loads is studied. The total load demand is met from the energy generated from renewable energy sources like solar, wind and fuel cells, the UPS system and the grid. The power consumed and the power fed back to the grid in a day is analyzed and found to be well within the standards. It is seen that the energy is fed back to the grid whenever the generated energy at the load side exceeds the demand. Also, the voltage fluctuations at PCC are observed for various load conditions.

\section{REFERENCES}

[I] X. Guan, Z, Xu, and Q. S. Jia, "Energy-efficient buildings facilitated by microgrid," IEEE Trans, Smart Grid, vol. 1, no. 3. pp. $243-252,2010$

[2] Tesoro Elana Del Carpio Huayllus,Dorel Soares Ramos and Ricardo Leon Vasquez, Amez, "Microgrid Systems: Main Incentive Policies and Performance Constraints Evaluation for their Integration to the Network", IEEE Trans. Latin America Volume 12, Issue 6, September, 2014.

[3] Hussai Basha Sh, Venkatesh P, "Control of Solar Photovoltaic (PV) Power Generation in Grid-Connected and islanded microgrids," International Journal of Engineering Research and General Science Volume 3, Issue 3, Part-2. May-June, 2015.

[4] C. L, Moreira, and A. G. Madureira, "Defining Control Strategies for MicroGrids Islanded Operation" IEEE Trans. On PowerSystems, Volume 21, No. 2, MAY 2006. 
[5] C. L. Moreira, F. O. Resende, and J. A. Peças Lopes, Senior Member, IEEE, "Using Low Voltage MicroGrids for Service Restoration" IEEE Trans. On PowerSystems, Volume 22, NO. I, FEBRUARY 2007

\section{APPENDIX}

\begin{tabular}{|c|c|c|c|c|c|c|}
\hline $\begin{array}{l}\text { Time } \\
\text { (hrs.) }\end{array}$ & $\begin{array}{l}\text { Use } \\
{[\mathrm{kW}]}\end{array}$ & $\begin{array}{l}\text { Gen } \\
{[\mathrm{kW}]}\end{array}$ & $\begin{array}{l}\text { Grid } \\
{[\mathrm{kW}]}\end{array}$ & $\begin{array}{l}\text { Solar } \\
{[\mathrm{kW}]}\end{array}$ & $\begin{array}{l}\text { Fuel } \\
\text { Cell[KW] }\end{array}$ & $\begin{array}{l}\text { UPS } \\
{[\mathrm{KW}]}\end{array}$ \\
\hline 0.00 & 6.46 & 0.00 & 4.46 & 0.00 & 1.00 & 1.00 \\
\hline 1.00 & 6.39 & 0.00 & 4.39 & 0.00 & 1.00 & 1.00 \\
\hline 2.00 & 4.56 & 0.00 & 2.56 & 0.00 & 1.00 & 1.00 \\
\hline 3.00 & 2.41 & 0.00 & 0.41 & 0.00 & 1.00 & 1.00 \\
\hline 4.00 & 2.44 & 0.00 & 0.44 & 0.00 & 1.00 & 1.00 \\
\hline 5.00 & 2.41 & 0.00 & 0.41 & 0.00 & 1.00 & 1.00 \\
\hline 6.00 & 2.42 & 0.00 & 0.42 & 0.00 & 1.00 & 1.00 \\
\hline 7.00 & 2.52 & 0.00 & 0.52 & 0.00 & 1.00 & 1.00 \\
\hline 8.00 & 2.42 & 0.20 & 0.23 & 0.20 & 1.00 & 1.00 \\
\hline 9.00 & 3.06 & 1.23 & -0.16 & 1.23 & 1.00 & 1.00 \\
\hline 10.00 & 2.80 & 2.20 & -1.40 & 2.20 & 1.00 & 1.00 \\
\hline 11.00 & 2.65 & 3.17 & -2.52 & 3.17 & 1.00 & 1.00 \\
\hline 12.00 & 2.30 & 3.80 & -3.51 & 3.80 & 1.00 & 1.00 \\
\hline 13.00 & 6.91 & 4.20 & 0.70 & 4.20 & 1.00 & 1.00 \\
\hline 14.00 & 7.31 & 4.38 & 0.94 & 4.38 & 1.00 & 1.00 \\
\hline 15.00 & 3.42 & 4.22 & -2.80 & 4.22 & 1.00 & 1.00 \\
\hline 16.00 & 2.91 & 3.68 & -2.77 & 3.68 & 1.00 & 1.00 \\
\hline 17.00 & 2.77 & 2.85 & -2.08 & 2.85 & 1.00 & 1.00 \\
\hline 18.00 & 7.27 & 1.57 & 3.70 & 1.57 & 1.00 & 1.00 \\
\hline 19.00 & 2.82 & 0.49 & 0.33 & 0.49 & 1.00 & 1.00 \\
\hline 20.00 & 6.59 & -9.08 & 4.66 & 0.08 & 1.00 & 1.00 \\
\hline 21.00 & 7.99 & 0.00 & 5.99 & 0.00 & 1.00 & 1.00 \\
\hline 22.00 & 7.86 & 0.00 & 5.86 & 0.00 & 1.00 & 1.00 \\
\hline 23.00 & 6.62 & 0.00 & 4.63 & 0.00 & 1.00 & 1.00 \\
\hline 24.00 & 6.51 & 0.00 & 4.51 & 0.00 & 1.00 & 1.00 \\
\hline & & & & & & \\
\hline
\end{tabular}

